\title{
Marein Regulates Insulin Resistance in Diabetic Nephropathy Mice by Inducing Autophagy
}

\author{
Marein Regula la Resistencia a la Insulina en Ratones \\ con Nefropatía Diabética Induciendo la Autofagia
}

\author{
Tian Li1; Zulipiya Abula²; Kedireya kadier³; Yanli Guo ${ }^{3}$; Lifeng Wang4; \\ Yongwei Zhang'; Zheng Ran ${ }^{3}$; Zhipeng Song ${ }^{3}$; Fang Zhang ${ }^{1}$ \& Xinmin Mao ${ }^{2}$
}

\begin{abstract}
LI, T.; ABULA, Z.; KADIER, K.; GUO, Y.; WANG, L.; ZHANG, Y.; RAN, Z.; SONG, Z.; ZHANG, F. \& MAO, X. Marein regulates insulin resistance in diabetic nephropathy mice by inducing autophagy. Int. J. Morphol., 39(6):1635-1645, 2021.

SUMMARY: Marein is the main active substance of Coreopsis tinctoria nutt. It not only has anti-oxidation and anti-tumor effects, but also can lower blood lipid, prevent high blood glucose, improve insulin resistance, inhibit gluconeogenesis and promote glycogen synthesis. However, the exact mechanism of its action is still unclear. Here, we explored the effect and mechanism of Marein on insulin resistance. The mice were divided into $\mathrm{db} / \mathrm{m}, \mathrm{db} / \mathrm{db}$, metformin $+\mathrm{db} / \mathrm{db}$, and marein $+\mathrm{db} / \mathrm{db}$ groups. The body weight and kidney weight were recorded. Serum biochemical and renal function tests were measured after 8 weeks of continuous administration. Kidney tissues were subjected to HE staining, PAS staining, and Masson staining. The effect of marein on PI3K/Akt signal and autophagy pathway was detected by Western blot. After 8 weeks of Marein intervention, the body weight and kidney weight of mice did not change significantly, but the fasting blood glucose and blood lipid levels were significantly reduced than db/db group. Marein significantly improved the insulin resistance index, increased serum adiponectin and improved glucose and lipid metabolism disorders of $\mathrm{db} / \mathrm{db}$ mice. Moreover, marein improved the basement membrane thickness of glomeruli and tubules, improved glomerular sclerosis and tubular fibrosis, as well as renal insufficiency, thereby protecting kidney function and delaying the pathological damage. Furthermore, marein increased the expression of PI3K and the phosphorylation of Akt/Akt (Ser473), and promoted the expression of LC3II/I, Beclin1 and ATG5. Additionally, it promoted the expression of FGFR1 in the kidney of db/db mice, and promoted the increase of serum FGF21 and FGF23. Marein has a protective effect on the kidneys of diabetic mice. It protects diabetic nephropathy by regulating the IRS1/PI3K/Akt signaling pathway to improve insulin resistance. Therefore, marein may be an insulin sensitizer.
\end{abstract}

KEY WORDS: Marein; Insulin resistance; Diabetic nephropathy; Autophagy.

\section{INTRODUCTION}

Diabetes mellitus is a metabolic disease characterized by poor insulin secretion or insulin resistance and elevated blood glucose levels. According to the International Diabetes Federation (IDF) statistics (Cho et al., 2018), 425 million people worldwide suffered from diabetes, accounting for 8.8 $\%$ of the population aged 20-79 in 2017. It is estimated that by 2045 , there will be nearly 629 million diabetic patients in the world, accounting for $9.9 \%$ of the population aged 20-79 (Nov 18, 2019). In addition, in 2017, there were 114 million diabetic patients between the ages of 20 and 79 in China. Clinical statistics show that about $30-40 \%$ of diabetic patients will eventually develop diabetic nephropathy (DN) (Alicic et al., 2017).
DN is a common and serious complication of diabetes, mainly manifested as edema, proteinuria, and hypertension, which can lead to life-threatening renal failure (Heerspink et al., 2019). Insulin resistance is the core cause of diabetes (Umanath \& Lewis, 2018). As the target organ of insulin, the kidney expresses large amounts of insulin receptors, and patients with DN usually have systemic or renal insulin resistance (Wei et al., 2019). Therefore, improving insulin resistance is of great significance for the treatment and prevention of DN (Thomas \& Karalliedde, 2019). At present, the commonly used drugs for $\mathrm{DN}$ are glienet, insulin, and biguanide, which can be used to treat DN by combining strategies such as lowering blood glucose,

\footnotetext{
${ }^{1}$ Department of Histology and Embryology, School of Basic Medical Sciences, Xinjiang Medical University, Urumqi Xinjiang, China.

${ }^{2}$ College of Traditional Chinese Medicine, Xinjiang Medical University, Urumqi Xinjiang, China.

${ }^{3}$ Department of Pharmacology, Pharmacy College, Xinjiang Medical University, Urumqi Xinjiang, China.

${ }^{4}$ Department of Physiology, School of Basic Medical Sciences, Xinjiang Medical University, Urumqi Xinjiang, China.
} 
lowering blood lipids, and lowering blood pressure (MüllerWieland, 2018; Wang, 2018). However, these drugs may cause electrolyte disturbances in the long term, leading to increased kidney load, and orthostatic hypotension, etc. Till now, it is still difficult to prevent the occurrence of DN. Moreover, there is no specific medicine for DN (Yashkin et al., 2018).

Coreopsis tinctoria nutt is a plant of the Compositae family, native to North America and cultivated as a garden plant worldwide (Hwang et al., 2010; Wang et al., 2015). As a rare and unique alpine wild plant, Coreopsis tinctoria nutt is mainly planted in high-altitude and cold regions such as Tianshan, Hotan and Kashgar in Xinjiang, China. Studies have shown that Coreopsis tinctoria nutt has the effects of anti-oxidation, lowering blood pressure, lowering blood glucose, andlowering blood lipids (Yao et al., 2015; Jiang et al., 2018; Mu et al., 2020). Our previous research (Yao et al.) showed that the ethyl acetate extract of Coreopsis tinctoria nutt can improve blood glucose, blood lipids and kidney function in patients with DN. In addition, the ethyl acetate extract of Coreopsis tinctoria nutt can also inhibit diabetic nephritis and fibrosis (Dias et al., 2010a,b; Yao et al., 2015).Marein is one main active substance of Coreopsis tinctoria nutt. It not only has anti-oxidation and anti-tumor effects, but also can lower blood lipid, prevent high blood glucose, improve insulin resistance, inhibit gluconeogenesis and promote glycogen synthesis (Guo et al., 2020). However, the exact mechanism of its action is still unclear.

Studies have shown that insulin resistance causes the autophagy pathway of various organs and tissues to be significantly inhibited (Shintani \& Klionsky, 2004; Mizushima, 2007). Regulating the autophagy pathway improves insulin resistance and plays a role in the prevention and treatment of DN. In vitro experiments (Jiang et al., 2016) have shown that the promotive effect of marein on autophagy pathway may be one of the mechanisms for improving insulin resistance of human glomerular vascular endothelial cells. Therefore, this study aims to investigate the protective effect and underlying mechanism of marein on DN in a mouse model. Our findings may provide important evidence for the clinical management and treatment of DN.

\section{MATERIAL AND METHOD}

Animals. Six-week old db/db (a model for $\mathrm{DN}$ ) and $\mathrm{db} / \mathrm{m}$ mice (control for DN model) with average body weight of $28 \pm 2 \mathrm{~g}$ were from Changzhou Avanse Experimental Animals. The animals were kept in a specific pathogen free environment at $22 \pm 2{ }^{\circ} \mathrm{C}$ and $45 \pm 5 \%$ humidity and fed with normal diet. This study was conducted in strict accordance with the recommendations of the National Institutes of Health's Guide for the Care and Use of Laboratory Animals. All animal experiments were conducted according to the ethical guidelines of Animal Experimental Center, Xinjiang Medical University. All efforts were made to minimize animal suffering. All experimental protocols were approved by the Ethics Committee of Xinjiang Medical University.

Animal grouping, treatment and sampling. The mice were further randomly divided into $\mathrm{db} / \mathrm{m}$ group (control, $\mathrm{n}=10$ ), $\mathrm{db} / \mathrm{db}$ group (DN model, $\mathrm{n}=10), \mathrm{db} / \mathrm{db}+$ metformin $(280 \mathrm{mg} /$ $\mathrm{kg})$ (Brisol-Myers Squibb, USA) group $(\mathrm{n}=10)$, and $\mathrm{db} /$ $\mathrm{db}+$ marein $(50 \mathrm{mg} / \mathrm{kg})$ (Extrasynthese, France) group $(\mathrm{n}=10)$. Metformin and Marein were dissolved in $0.5 \%$ $(0.5 \mathrm{~g} / 100 \mathrm{~mL})$ sodium carboxymethyl cellulose and was administrated by gavage once every day for 8 weeks. The control group was treated with distilled water containing 0.5 $\%(0.5 \mathrm{~g} / 100 \mathrm{~mL})$ sodium carboxymethyl cellulose every day for 8 weeks. At 7 weeks of administration, $24 \mathrm{~h}$ urine samples were collected from mice. The body weight of mice was monitored every week. At the end of the experiments, all mice were sacrificed by cervical dislocation. The blood samples were collected from bulbus oculi. The left kidneys were rinsed with cold physiological saline solution, placed immediately in liquid nitrogen, and stored at $-80^{\circ} \mathrm{C}$ until use. The right kidneys were weighed and fixed in $10 \%$ formaldehyde.

Blood and urine biochemical analysis. The collected blood samples were centrifuged at $3000 \mathrm{rpm}$ for $10 \mathrm{~min}$. Serum samples were separated for detection of total cholesterol (TC), triglycerides, blood urea nitrogen (BUN), and serum creatinine (SCr), fibroblast growth factor 21 (FGF21), and fibroblast growth factor 23 (FGF23), on an automatic biochemical analyzer (BS-120; Mindray, China). Blood glucose concentrations were measured by Accu-Chek Active Blood Glucose Meter (Roche, Germany). Plasma insulin was measured by Ultra-Sensitive Mouse Insulin ELISA Kit (Morinaga, Tokyo, Japan). Urinary microalbumin excretion was measured by Murine Microalbumin ELISA (Exocell, Philadelphia, PA). HOMA-IR was calculated as [fasting serum insulin (mU/L) ¥ fasting plasma glucose (mmol/L)] / 22.5. Serum adiponectin (APN) was detected using mouse adiponectin ELISA Kit (Cusabio china).

Histopathological staining. Right kidney tissues were fixed in $10 \%$ formaldehyde, embedded in paraffin, and cut into $3 \mu \mathrm{m}$ sections. The tissue sections were stained with hematoxylin and eosin (H\&E), Masson's reagent and PAS for histological examination. The images were captured by light microscopy (SZX7-1093; Olympus, Japan) and ImagePro Plus 6.0 software was used to analyze results. 
Trasmission electron microscopy. Renal specimens were fixed in $2 \%$ glutaraldehyde/0.1 M phosphate buffer $(\mathrm{pH}$ 7.4) and $1 \%$ osmium tetroxide/ $0.1 \mathrm{M}$ phosphate buffer (pH 7.4). Samples were then dehydrated, embedded, and cut into ultrathin sections. A transmission electron microscope $(\mathrm{H}-$ 7500; Hitachi, Tokyo, Japan) was used to visualize ultrathin sections stained with uranyl acetate and lead citrate. Glomerular basement were measured to assess the function of glomeruli by Image-Pro Plus 6.0 software.

Immunohistochemical analysis. After deparaffinization and hydration, the sections were rinsed three times with PBS and treated with endogenous catalase inhibitors. After blocking with goat serum (Bioss Biotechnology, Beijing, China) for $30 \mathrm{~min}$ at room temperature, the samples were incubated with anti-p62 (Cell Signaling Technology), at 4 ${ }^{\circ} \mathrm{C}$ overnight. On the next day, the secondary horseradishperoxidase-conjugated antibody (Bioss Biotechnology) was added and incubated at $37^{\circ} \mathrm{C}$ for $30 \mathrm{~min}$. After rinsing three times with PBS, tissue sections were developed with diaminobenzidine tetrahydrochloride. The slices were observed by light microscopy (Olympus BX-43; Olympus Optical, Tokyo, Japan), and Image-Pro Plus 6.0 software was used to analyze results.

Western blot. The left kidneys were subject to lysis with RIPA (Thermo, USA) and protein samples were obtained after sonification and centrifugation. Protein concentration was determined by using BCA Protein Assay Kit (Thermo). The protein samples were separated by SDS-PAGE and then transferred to PVDF membranes (Millpore, USA). The
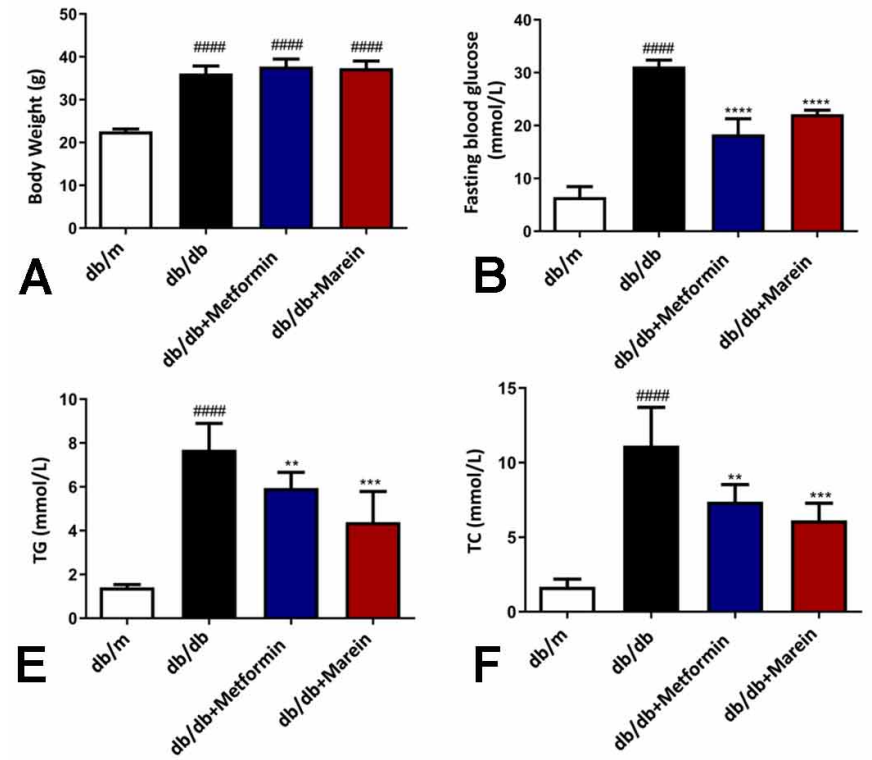

PVDF membranes were then blocked in a $5 \%$ skimmed milk solution for $2 \mathrm{~h}$ at room temperature and subsequently incubated with primary antibodies overnight at $4{ }^{\circ} \mathrm{C}$. The primary antibodies included those against p-AKT, p62, mTOR, AKT, IRS-1, PI3K, Beclin1, ATG5 and FGFR1 (fibrous growth factor receptor) (1:1000; Cell Signaling Technology, Danvers, MA, USA), and GAPDH $(1 ; 2000)$ were incubated at $4^{\circ} \mathrm{C}$ overnight. The membranes were then rinsed 3 times and incubated in the corresponding secondary antibodies (1:2000, Dingguo, China) at room temperature for $2 \mathrm{~h}$. After rinsing three times, bands were developed with ECL system (Amersham Biosciences, Little Chalfont, UK) and analyzed by an image analyzer (BioRad Laboratories). Image $\mathbf{J}$ software was used for densitometry measurements of protein bands on Western blots.

Statistical analysis. Statistical analyses were measured by SPSS 17.0 (Chicago, IL, USA). All data are presented as mean \pm standard deviation (SD) of three independent experiments. The comparison of two groups or multiple groups were analyzed using the Unpaired Student's t test and one-way ANOVA (S-N-K method for post hoc analysis), respectively. A $p$ value $<0.05$ was considered to be statistically significant.

\section{RESULTS}

Changes in body weight and metabolism of $\mathrm{db} / \mathrm{db}$ mice after receiving marein treatment. The body weights of mice were monitored. As shown in Figure 1A, the body

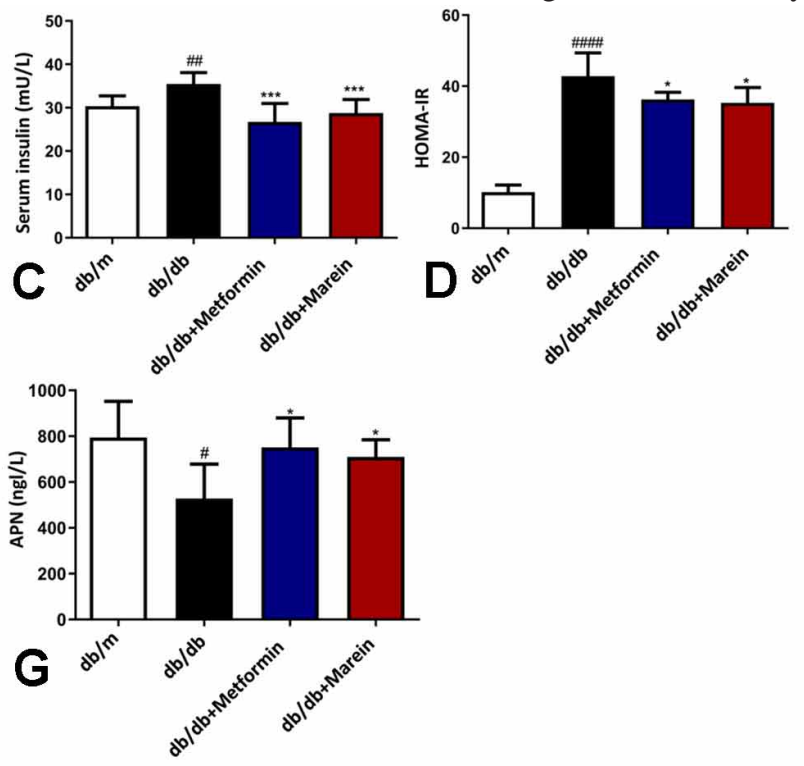

Fig. 1. Changes in body weight and metabolic parameters after treatment with marein. Six-week-old db/db mice received intragastric administration marein per day for 8 weeks. Body weight was monitored. Blood and urine samples were collected for biochemical analysis. (A) Body weight. (B) Fasting blood glucose. (C) Serum insulin. (D) HOMA-IR. (E) TG. (F) TC. (G) APN. The data are presented as the mean \pm SD. \#\# $\mathrm{p}<0.01$, \#\#\# $\mathrm{p}<0.001$, versus $\mathrm{db} / \mathrm{m}$ mice; $* \mathrm{p}<0.05$, ** $\mathrm{p}<0.01$, *** $\mathrm{p}<0.001$, versus db/db mice. 
weights of $\mathrm{db} / \mathrm{db}$ group, $\mathrm{db} / \mathrm{db}+$ metformin group, $\mathrm{db} /$ $\mathrm{db}+$ marein group were significantly higher than that of $\mathrm{db} / \mathrm{m}$ group $(\mathrm{P}<0.05)$. No significant difference was observed among $\mathrm{db} / \mathrm{db}$ group, $\mathrm{db} / \mathrm{db}+$ metformin group, and $\mathrm{db} / \mathrm{db}+$ marein group. Compared with the $\mathrm{db} / \mathrm{m}$ group, the fasting blood glucose levels (Fig. 1B), the serum insulin (Fig. 1C), HOMA-IR (Fig. 1D), TG (Fig. 1E) and TC (Fig. $1 F)$ of $d b / d b$ group increased significantly $(P<0.05)$. However, compared with $\mathrm{db} / \mathrm{db}$ group, the levels of these factors in $\mathrm{db} / \mathrm{db}+$ metformin and $\mathrm{db} / \mathrm{db}+$ marein groups were significantly reduced $(\mathrm{P}<0.05)$. In addition, the $\mathrm{db} / \mathrm{db}$ group had significantly lower APN level than $\mathrm{db} / \mathrm{m}$ group $(\mathrm{P}<0.05)$ (Fig. $1 \mathrm{G})$; meanwhile the $\mathrm{db} / \mathrm{db}+$ metformin and $\mathrm{db} / \mathrm{db}+$ marein groups had significantly higher APN level than $\mathrm{db} / \mathrm{db}$ group $(\mathrm{P}<0.05)$. These results indicated that marein could improve glucose and lipid metabolism in DN mice.

Marein improves kidney function in $\mathrm{db} / \mathrm{db}$ mice. In order to examine the effect of marein on improving the kidney function of $\mathrm{db} / \mathrm{db}$ mice, we measured kidney weight, plasma Scr, BUN and urine microalbumin levels. The results showed that after 8 weeks of treatment, the kidney weights of $\mathrm{db} / \mathrm{db}$ group, $\mathrm{db} / \mathrm{db}+$ metformin group, $\mathrm{db} / \mathrm{db}+$ marein group were significantly higher than that of $\mathrm{db} / \mathrm{m}$ group $(\mathrm{P}<0.05)$ (Fig. $2 \mathrm{~A})$. There were no significant differences among $\mathrm{db} / \mathrm{db}, \mathrm{db} / \mathrm{db}+$ metformin, and $\mathrm{db} /$ $\mathrm{db}+$ marein groups. Compared with $\mathrm{db} / \mathrm{m}$ group, the $\mathrm{db} / \mathrm{db}$ group had significantly higher Scr (Fig. 2B), BUN (Fig. $2 \mathrm{C})$ and urine microalbumin (Fig. 2D) $(\mathrm{P}<0.05)$. Compared with the $\mathrm{db} / \mathrm{db}$ group, the treatment of metformin and marein significantly decreased the levels of Scr (Fig. 2B), BUN (Fig. 2C) and urine microalbumin (Fig. 2D) $(\mathrm{P}<0.05)$. These results indicate that marein may improve kidney filtration function and protect $\mathrm{db} / \mathrm{db}$ mice from damage.

Marein reduces kidney damage in $\mathrm{db} / \mathrm{db}$ mice. To evaluate the histological changes, the kidney sections were stained with HE (Fig. 3A). The results showed that the structure of glomerulus and renal tubule in $\mathrm{db} / \mathrm{m}$ group
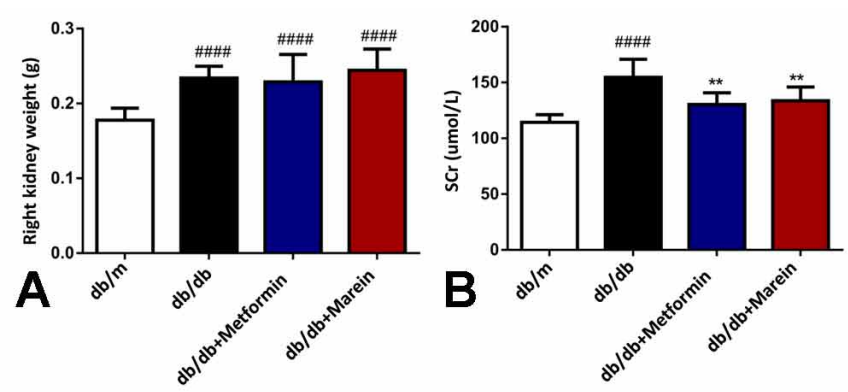

Fig. 2. Marein improved renal function in $\mathrm{db} / \mathrm{db}$ mice after treatment with marein.(A) Right kidney weight, (B) Scr, (C) BUN, and (D) Urine microalbumin were measured. The data are presented as the mean $\pm \mathrm{SD}$. \#\#p $<0.01$, \#\#\#p $<0.001$, versus $\mathrm{db} / \mathrm{m}$ mice; * $\mathrm{p}<0.05$, $* * \mathrm{p}<0.01, * * * \mathrm{p}<0.001$, versus $\mathrm{db} / \mathrm{db}$ mice.
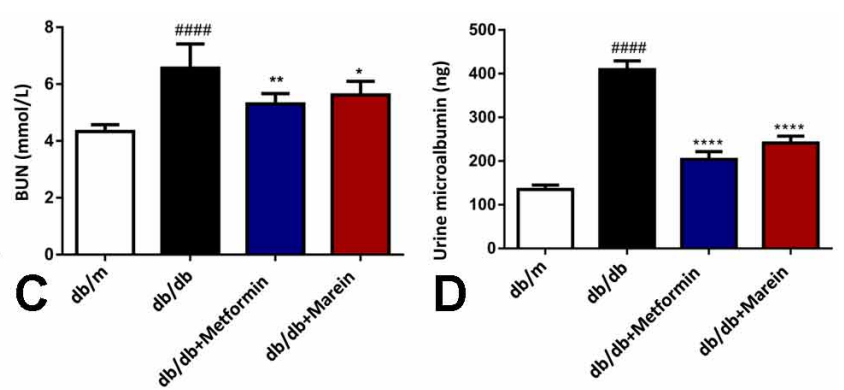

was normal, and there was no obvious abnormality. The glomerulus of the model group was irregular in shape, with hyperplasia of fibrous tissue, obviously reduced capillaries, and infiltration of lymphocytes and monocytes. In the metformin and marein groups, the degree of fibrous hyperplasia was reduced, the capillary loop was increased, and inflammatory cells were still infiltrated to a certain extent. HE staining results suggested that marein could alleviate the damage of renal tissue structure in DN mice.

There were no abnormal changes in the structure of glomeruli and renal tubules in $\mathrm{db} / \mathrm{m}$ group, and the collagen fiber staining was normal (Fig. 3B). In the model group, the glomerular basement membrane was thickened; the mesangial membrane showed hyperplasia; and, the collagen fiber staining was obvious. A large amount of blue-stained material was deposited in the renal vesicles and tubules, and the collagen fiber deposition was obvious in the renal interstitium. After administration of metformin and marein, the collagen fibers of the glomerular basement membrane were less stained and the thickening of the basement membrane and mesangium was reduced. Compared with the model group, both marein and metformin significantly improved the deposition of collagen fibers in the glomerular interstitium $(\mathrm{P}<0.05)$.

Pathological sections of the kidney of mice in each group were stained with PAS, and morphological changes were observed (Fig. 3C). There was no abnormality in the structure of the glomerulus and renal tubule in the $\mathrm{db} / \mathrm{m}$ group. The $\mathrm{db} / \mathrm{db}$ mice in the model group showed hyperplasia of glomerular mesangial cells, obvious glycogen deposition in a mesangial matrix, thickening of basal membrane, and hyaline changes in the capillary loop. Metformin and Marion improved the pathological structure of glomerulus in DN mice. The basement membrane was more intact; and the thickening of basement membrane and the deposition of glycogen in the glomerulus and renal tubules were reduced. Statistically, the glycogen area score was significantly lower $(\mathrm{P}<0.05)$. 

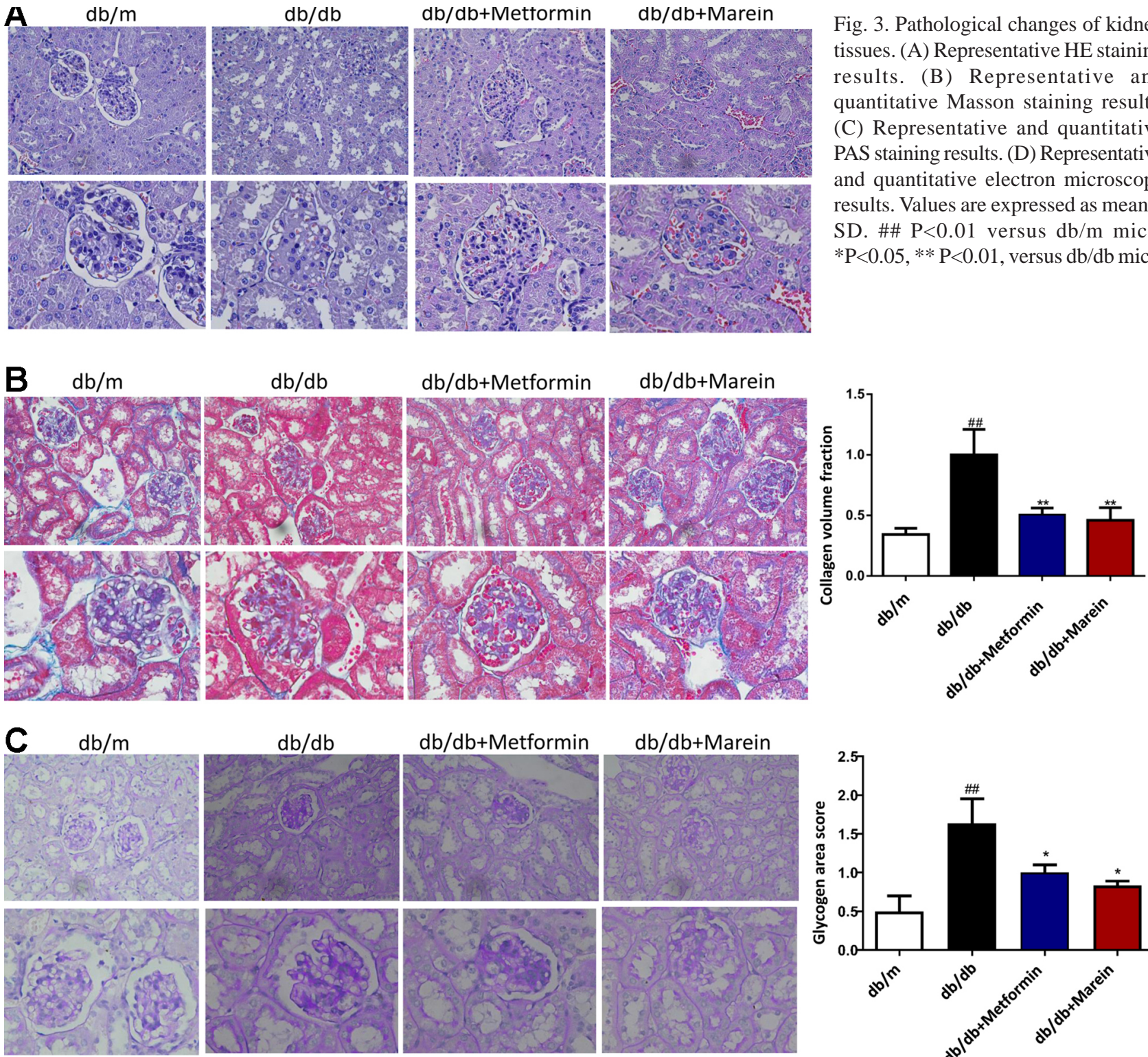

$\mathrm{db} / \mathrm{db}+$ Metformin
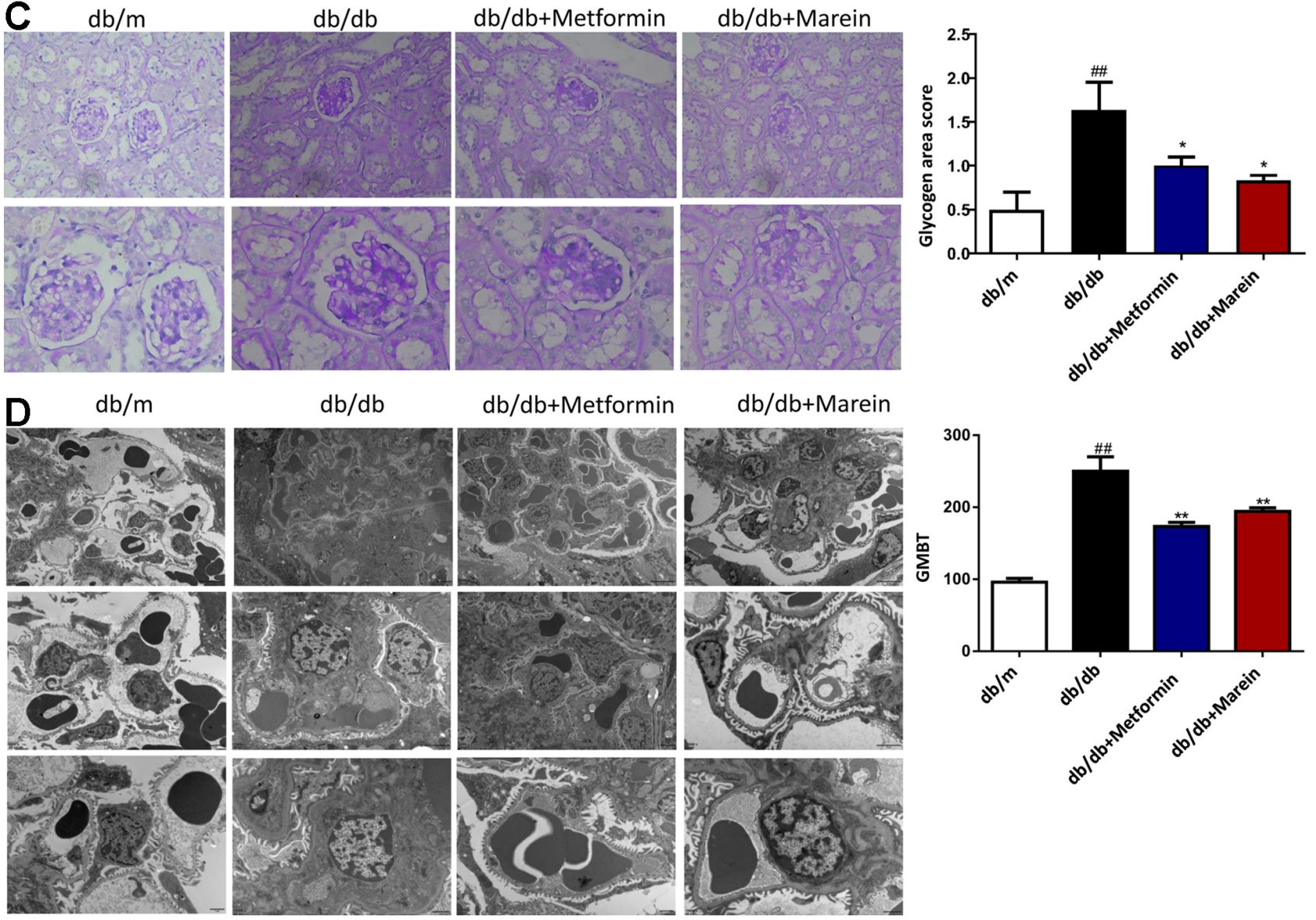
Furthermore, the pathological changes of kidney were observed by electron microscopy (Fig. 3D). In the $\mathrm{db} / \mathrm{m}$ group, the glomerular structure was normal under electron microscopy, and no obvious abnormalities were observed in endothelial cells, podocytes, and mesangial cells of capillaries. The glomerular basement membrane was normal and uniform in thickness. The morphology of podocytes was complete, and the structure of foot processes was clear, without obvious fusion. The glomerular basement membrane of $\mathrm{db} / \mathrm{db}$ mice in the model group showed obvious segmental thickening. Electron dense deposition was observed in subendothelial layer and basal membrane. Mesangial matrix was increased. The basal membrane of endothelial cells showed local hyperplasia. Podocyte arrangement was disordered, and podocytes were fused. In the metformin and Marein group, the thickening of glomerular basement membrane was reduced. Only a small amount of basement membrane showed segment thickening. Mesangial cells and

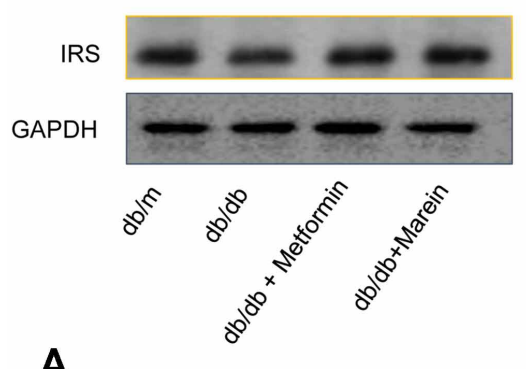

A

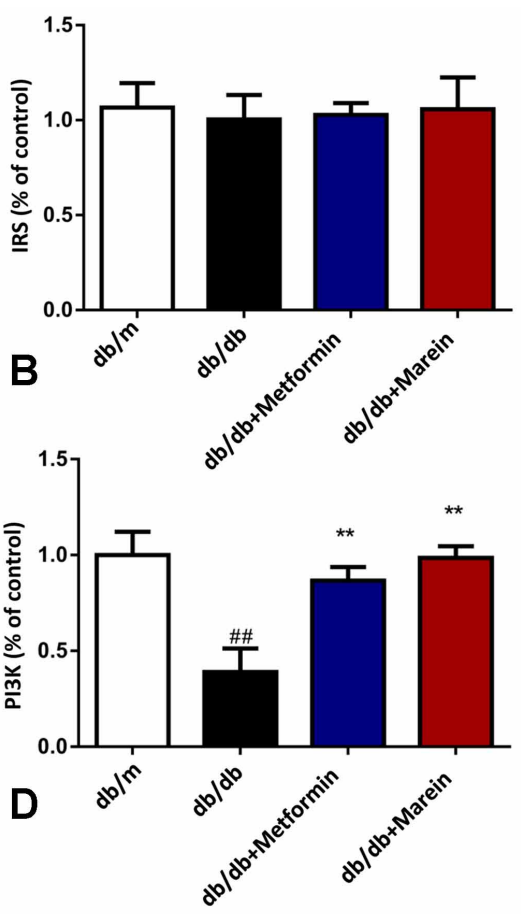

C

PI3K

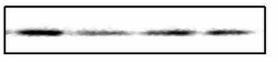

GAPDH

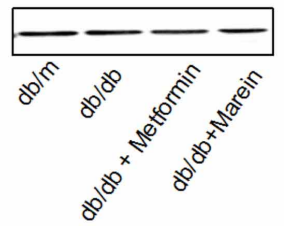

p-AKT

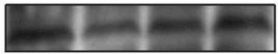

AKT

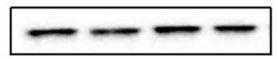

GAPDH
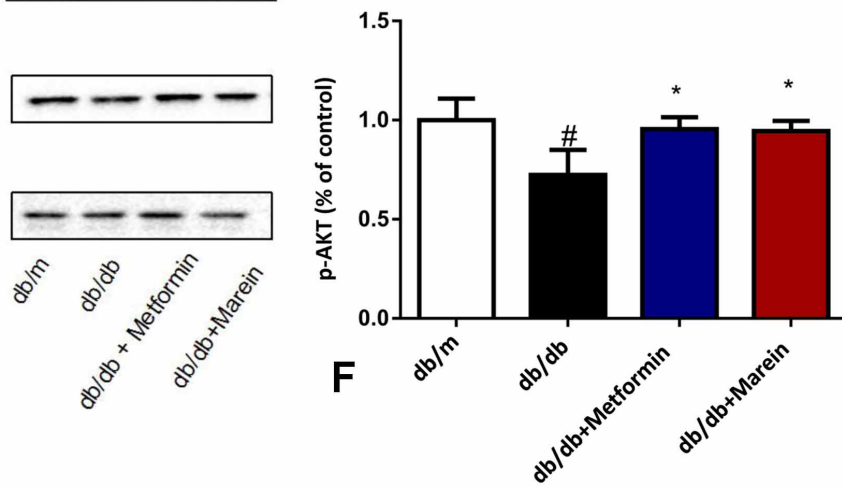

matrix proliferation were reduced; the foot process structure was normal; and the disorder of podocyte arrangement was also reduced. Statistically, compared with control group, the glomerular basement membrane thickness in the model group was significantly increased $(\mathrm{P}<0.01)$. Compared with the model group, the glomerular basement membrane thickness was significantly decreased in the Marein group and the metformin group $(\mathrm{P}<0.01)$. These results indicate that marein may protect DN mice from glomerulopathy and podocyte loss. In addition to glomerular disease, marein treatment reduced renal tubular damage and collagen accumulation in DN mice, indicating that marein could protect the DN kidney from structural and functional damage.

Marein regulates insulin resistance in $\mathrm{db} / \mathrm{db}$ mice. In order to explore the effect of marein on insulin resistance in $\mathrm{db} / \mathrm{db}$ mice, we detected the expression of insulin resistance-related proteins in the kidney tissue of $\mathrm{db} / \mathrm{db}$ mice by Western blot. Figures $4 \mathrm{~A}$ and $4 \mathrm{~B}$ showed that there was no significant change in IRS among four groups (all $\mathrm{P}>0.05$ ). Compared with the $\mathrm{db} / \mathrm{m}$ group, the level of PI3K (Fig. $4 \mathrm{C}$ and 4D) and p-Akt/Akt (Figs. 4E and 4F) in the kidney tissue of the $\mathrm{db} / \mathrm{db}$ group decreased significantly $(\mathrm{P}<0.01)$. However, the $\mathrm{db} / \mathrm{db}+$ metformin and $\mathrm{db} /$ $\mathrm{db}+$ marein groups had significantly lower level of PI3K (Figs. 4C and 4D) and pAkt/Akt (Figs. 4E and 4F) $(\mathrm{P}<0.05)$. These results indicated that marein might improve insulin resistance and insulin sensitivity by PI3K/Akt signaling pathway in $\mathrm{db} / \mathrm{db}$ mice.

Marein promotes the activation of the autophagy in the kidney of $\mathrm{db} / \mathrm{db}$ mice. In the state of insulin resistance, the autophagy of kidney tissue is defective. Therefore, regulating autophagy can improve insulin resistance and prevent the development of DN. We tested the expression of autophagy-related proteins, including LC3II, LC3I, ATG5, p62 and

Fig. 4. Marein treatment changed renal insulin resistance. Western blot was conducted to detect protein expression levels of (A and B) IRS, (C and D) PI3K, (E and F) p-Akt and Akt in kidney tissues. The data are presented as the mean \pm SD. $\#$ p $<0.05$, \#\#p < 0.01, versus $\mathrm{db} / \mathrm{m}$ mice; $* \mathrm{p}<0.05, * * \mathrm{p}<0.01$, versus $\mathrm{db} / \mathrm{db}$ mice. 
Beclin 1 with Western blot. The results showed that compared with the $\mathrm{db} / \mathrm{db}$ group, marein inhibited the expression of $\mathrm{p}$ mTOR in db/db mice (Figs. 5A and 5B). Compared with the $\mathrm{db} / \mathrm{db}$ group, marein treatment promoted the expression of LC3II/LC3I, ATG5 and Beclin 1 in db/db mice, and reduced the level of p62 (Figs. 5C-5F), indicating that marein promotes the activation of the autophagy pathway in $\mathrm{db} / \mathrm{db}$ mice.

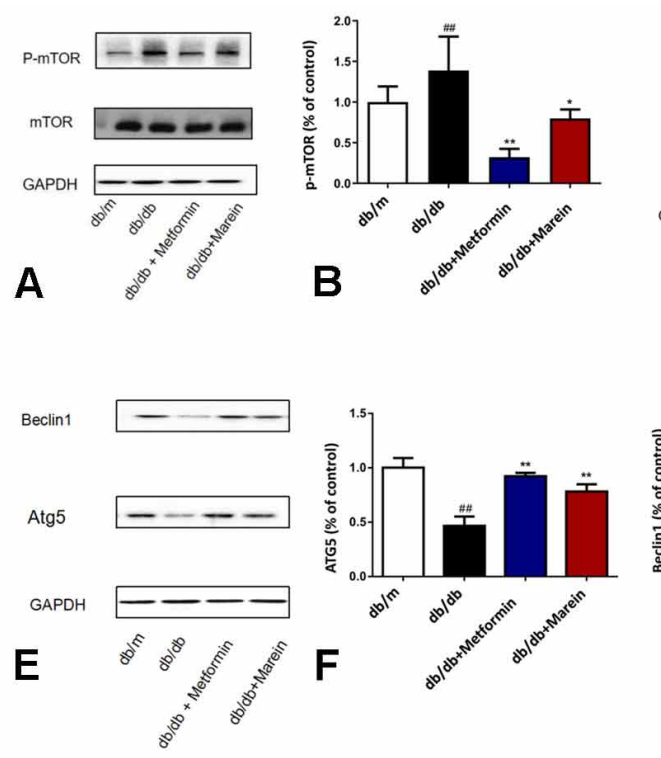

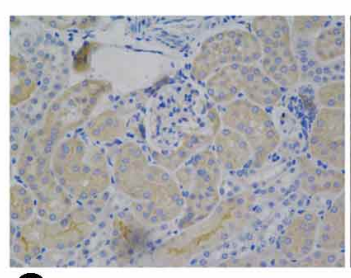

G $\quad d b / m$

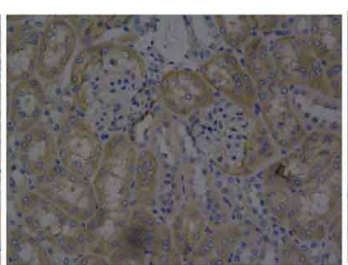

$\mathrm{db} / \mathrm{db}$
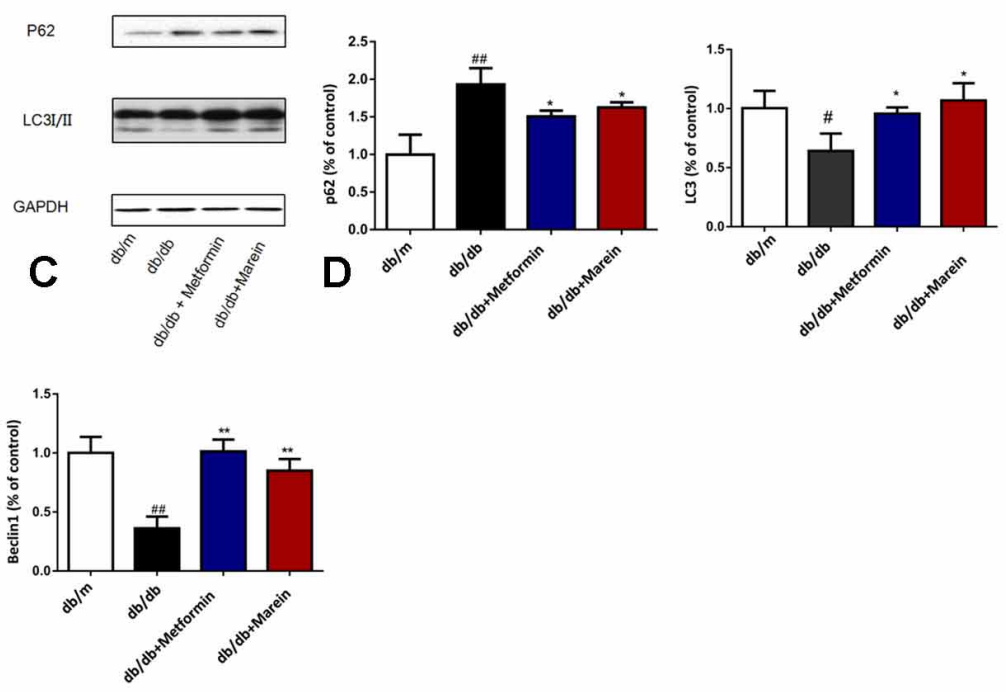

Immunohistochemical staining was used to locate and quantitatively analyze p62 expression in renal tissues. As shown in Figure 5G, p62 expression in the model group was higher than that in other groups. Statistically, compared with $\mathrm{db} / \mathrm{m}$ normal mice, p62 expression in glomeruli and renal tubules was significantly increased in the $\mathrm{db} / \mathrm{db}$ group $(\mathrm{P}<0.05)$, and both metformin and marein intervention could decrease p62 expression $(\mathrm{P}<0.05)$.

Fig. 5. Marein treatment changed renal autophagy.(A and B) p-mTOR and mTOR, (C and D) LC3I/II and p62, (E and F) ATG5 and Beclin in kidney tissues were detected by Western blot, respectively. (G) Immunohistochemical staining of p62 in kidney tissues. Representative and quantitative results were shown. The data are presented as the mean $\pm \mathrm{SD}$. \#p $<0.05$, \#\#p $<0.01$, \#\#\#p $<0.001$, versus $\mathrm{db} / \mathrm{m}$ mice; $* \mathrm{p}<0.05, * * \mathrm{p}<0.01$, versus $\mathrm{db} / \mathrm{db}$ mice.
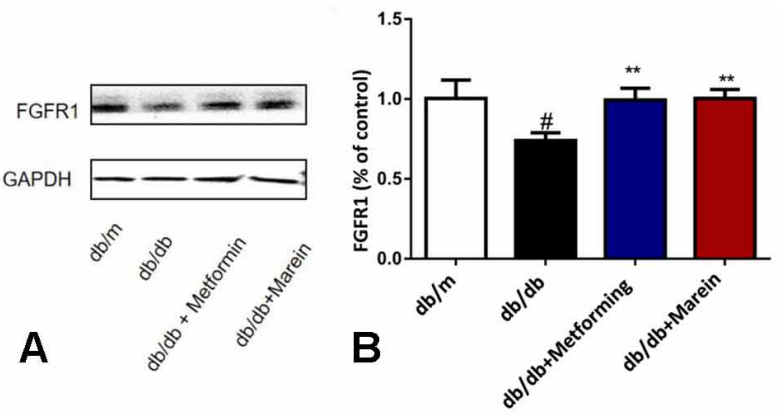
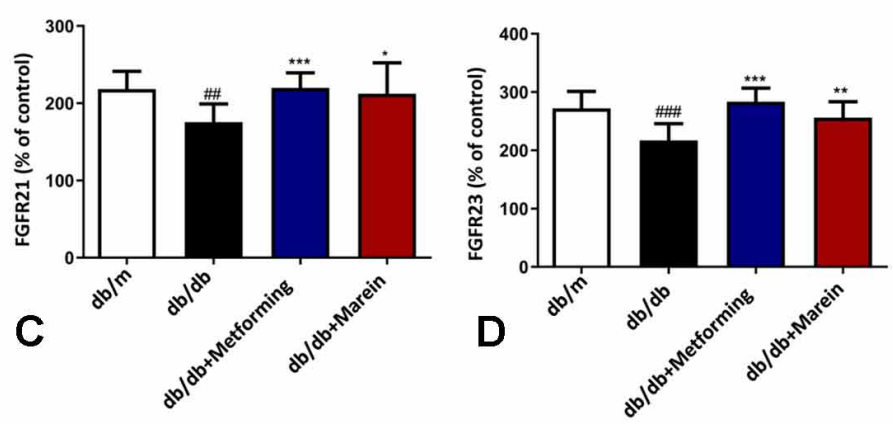

Fig. 6. Effect of marein treatment on FGFR1, FGF21 and FGF23. Western blot was used to analyze protein expression levels of FGFR1 (A and B) in kidney tissues. Serum FGF21 (C) and FGF23 (D) were also detected. The data are presented as the mean \pm SD. \#p $<0.05$, $\# \# p<0.01, \# \#$, $<0.001$, versus $\mathrm{db} / \mathrm{m}$ mice; $* \mathrm{p}<0.05, * * \mathrm{p}<0.01$, ***p $<0.001$, versus $\mathrm{db} / \mathrm{db}$ mice. 
Effect of marein on kidney FGFR1, serum FGF21 and FGF23 in db/db mice. We performed Western blot to test the effect of marein on the expression of FGFR1 in the kidney tissue of $\mathrm{db} / \mathrm{db}$ mice. As shown in the Figures $6 \mathrm{~A}$ and $6 \mathrm{~B}$, compared with the $\mathrm{db} / \mathrm{m}$ group, the expression level of FGFR1 in the $\mathrm{db} / \mathrm{db}$ group was significantly reduced. After 8 weeks of metformin and marein treatment, the expression level of FGFR1 in the kidney tissue increased significantly $(\mathrm{P}<0.01)$ (Figs. 6A and 6B). Moreover, the FGF21 ( $\mathrm{P}<0.01)$ (Fig. 6C) and FGF23 (P $<0.001$ ) (Fig. 6D) of the $\mathrm{db} / \mathrm{db}$ mice were significantly reduced compared with the $\mathrm{db} / \mathrm{m}$ group. Metformin and marein significantly increased FGF21 and FGF23 $(\mathrm{P}<0.01)$.

\section{DISCUSSION}

In this study, we demonstrated the renal protective effect of marein on $\mathrm{db} / \mathrm{db}$ mice. After 8 weeks of treatment with marein, the blood glucose and lipid metabolism disorders of diabetic mice were improved. In addition, marein treatment significantly improved the renal function, including $\mathrm{BUN}, \mathrm{SCr}$ and urine microalbumin. Histopathological analysis also showed that marein reduced glomerular and tubular damage and collagen accumulation in $\mathrm{db} / \mathrm{db}$ mice.

Abnormal blood glucose and blood lipids are risk factors for DN (Li et al., 2020). Clinical studies (Calle \& Hotter, 2020; Donate-Correa et al., 2020; Nunes et al., 2020) have shown that persistent high blood glucose and large amounts of hyperlipidemia will increase the production of reactive oxygen species in the body and induce kidney inflammation and oxidative stress. The main pathological changes of DN are the thickening of the glomerular basement membrane and the increase of the mesangial matrix, which leads to a decrease in glomerular filtration rate, accompanied by proteinuria, urea nitrogen and creatinine increase (Porrini et al., 2015; Alicic et al.). Here, we found that marein improved glucose and lipid metabolism disorders in DN mice, reduced glomerular and tubular damage caused by DN, and improved kidney function.

As the target organ of insulin, the kidney has a large number of insulin receptors. DN has systemic or renal insulin resistance (Pina et al., 2020). Therefore, improving the insulin sensitivity and insulin resistance of kidney tissue is a prevention and treatment strategy for DN (Xu et al., 2020). We showed that marein improved glucose and lipid metabolism in DN mice, inhibited the decline of renal function, glomerular and tubular damage, and up-regulated $\mathrm{PI} 3 \mathrm{~K}$ and $\mathrm{pAkt} / \mathrm{Akt}$ expression, suggesting that marein can improve insulin resistance and insulin sensitivity in $\mathrm{db} / \mathrm{db}$ mice. Therefore, marein may be an insulin sensitizer.

$\mathrm{PI} 3 \mathrm{~K} / \mathrm{AKT}$ is closely related to the occurrence and development of diabetes (Huang et al., 2018), and its regulatory signals and downstream molecules are considered to be the most promising targets for the treatment of DN (Maffei et al., 2018). In the state of insulin resistance, a large number of dysfunctions and components in cells are damaged, leading to intracellular stress response and inflammation (Moreno et al., 2018; Sagoo \& Gnudi, 2018). Therefore, the regulation of autophagymay improve insulin resistance in type 2 diabetes (Yang et al., 2020). We believe that autophagy may be a new prevention and treatment strategy to improve insulin resistance. In our study, db/db mice treated with marein showed a significant increase in the activation of the autophagy pathway, including related proteins (ATG5, Beclin1 and LC3B-II). All these indicate that enhanced autophagy activity can help delay the development of diabetes.

P62 is an autophagy receptor, which can bind to autophagosomes that degrade LC3B after fusion of ubiquitinated proteins with lysosomes (Wen et al., 2020). Therefore, it can be used as an indicator of autophagy degradation, acting as an autophagy receptor and signaling hub (Liu et al., 2020). In this study, immunohistochemical staining showed that the expression of p62 in the kidneys of diabetic mice was significantly higher than that in the control group, while treatment with marein significantly reduced the expression of p62. These results indicate that autophagy is inhibited in diabetic mice, and marein could promote autophagy.

We also found that after 8 weeks of marein intervention in $\mathrm{db} / \mathrm{db}$ mice, the expression level of mTOR protein in kidney tissues decreased. mTOR is a downstream signal protein of PI3K/AKT pathway (Zhang et al., 2019) and plays a central role in autophagy (Li et al., 2017). When the human body is over-nourished, mTOR activation can inhibit autophagy activity. When the human body is in a state of starvation, nutritional deficiency and cellular stress, mTOR is inhibited and autophagy is initiated (Lantier et al., 2020). The activation of mTOR signaling pathway can aggravate the development of DN (Wen et al.). Here, we found that marein could inhibit mTOR, thereby activating the autophagy pathway and playing a role in kidney protection.

Our results showed that treatment of $\mathrm{db} / \mathrm{db}$ mice with marein for 8 weeks significantly up-regulated the 
expression of FGFR1 in kidney tissues and increased the levels of FGF21 and FGF23 in serum. A large number of studies (Yuan et al., 2017; Wang et al., 2018) have shown that FGFR1 can promote autophagy.FGF21 and FGF23 are important members of the fibroblast growth factor family (Yamamoto et al., 2020). FGF21 is a new metabolic regulator that can increase the body's metabolic level and promote glucose uptake (Aljohani et al., 2019). In addition, FGF21 participates in the metabolism of glycolipid substances in the body, thereby increasing the body's energy consumption, regulating blood lipids, enhancing the absorption of glucose by fat cells, and inhibiting the secretion of glucagon. Studies (Talukdar et al., 2016; Mottillo et al., 2017) have shown that increased expression of FGF21 can significantly reduce the body weight of type 2 diabetic mice, lower blood glucose levels, promote blood glucose reabsorption, and maintain the function and number of islet cells. FGF23 is a hormone-like fibroblast growth factor newly identified in recent years (Bär et al., 2019). It is mainly produced by bone cells and secreted into the blood. It participates in the regulation of calcium and phosphorus levels and vitamin D (Trummer et al., 2019). It is also related to pathological processes such as abnormal glucose, lipid metabolism and insulin resistance (Fayed et al., 2018). Abnormal serum FGF-23 levels in patients with $\mathrm{T} 2$ diabetes are closely related to the occurrence of DN and other microangiopathy (Zhang et al., 2018).

\section{CONCLUSIONS}

In conclusion, we demonstrated that marein reduced kidney damage, glomerular and tubular damage, and collagen accumulation in $\mathrm{db} / \mathrm{db}$ mice. We also found that marein induced autophagy and enhanced the insulin sensitivity of the kidney by activating the PI3K/AKT signaling pathway, thereby improving DN. Our findings may have a positive role in the mechanism research and clinical drug treatment of DN.

\section{FUNDING}

This work was supported by Xinjiang Uygur Autonomous Region University Research program (No: XJEDU2020Y021), Natural Science Foundation of Xinjiang Uygur Autonomous Region (No: 2018D01C181), and the Key Project of National Natural Science Foundation of China and Xinjiang Mutual Funds (No: U1303223 and 81560671).
LI, T.; ABULA, Z.; KADIER, K.; GUO, Y.; WANG, L.; ZHANG, Y.; RAN, Z.; SONG, Z.; ZHANG, F. \& MAO, X. Marein regula la resistencia a la insulina en ratones con nefropatía diabética induciendo la autofagia. Int. J. Morphol., 39(6):1635$1645,2021$.

RESUMEN: Marein es la principal sustancia activa de Coreopsis tinctoria nutt. No solo tiene efectos antioxidantes y antitumorales, sino que también puede reducir los lípidos en sangre, prevenir la glucemia alta, mejorar la resistencia a la insulina, inhibir la gluconeogénesis y promover la síntesis de glucógeno. Sin embargo, el mecanismo exacto de su acción aún no está claro. Se analizó el efecto y el mecanismo de Marein sobre la resistencia a la insulina. Los ratones se dividieron en grupos $\mathrm{db} / \mathrm{m}$, $\mathrm{db} / \mathrm{db}$, metformina $+\mathrm{db} / \mathrm{db}$ y mareína $+\mathrm{db} / \mathrm{db}$. Se registró el peso corporal y el peso de los riñones. Se midieron las pruebas de función renal y bioquímica sérica después de 8 semanas de administración continua. Los tejidos renales se sometieron a tinción HE, tinción PAS y tinción Masson. El efecto de la mareína sobre la señal de PI3K / Akt y la vía de autofagia se detectó mediante Western blot. Al término de 8 semanas de tratamiento con mareína, el peso corporal y el peso de los riñones de los ratones no cambiaron significativamente, pero los niveles de glucosa en sangre y lípidos en sangre en ayunas se redujeron significativamente en relación a los del grupo $\mathrm{db} / \mathrm{db}$. Marein mejoró significativamente el índice de resistencia a la insulina, aumentó la adiponectina sérica y mejoró los trastornos del metabolismo de la glucosa y los lípidos de los ratones db / db. Además, la mareína mejoró el grosor de la membrana basal de los glomérulos y túbulos, mejoró la esclerosis glomerular y la fibrosis tubular, así como la insuficiencia renal, protegiendo la función renal y retrasando el daño patológico. Además, la mareína aumentó la expresión de PI3K y la fosforilación de Akt / Akt (Ser473), y promovió la expresión de LC3II / I, Beclin1 y ATG5. Además, promovió la expresión de FGFR 1 en el riñón de ratones $\mathrm{db}$ / db y el aumento de FGF21 y FGF23 en suero. Marein tiene un efecto protector sobre los riñones de ratones diabéticos. Protege la nefropatía diabética regulando la vía de señalización IRS1 / PI3K / Akt para mejorar la resistencia a la insulina. Por tanto, la mareína puede ser un sensibilizador a la insulina.

PALABRAS ClAVE: Marein; Resistencia a la insulina; Nefropatía diabética; Autofagia.

\section{REFERENCES}

Alicic, R. Z.; Rooney, M. T. \& Tuttle, K. R. Diabetic kidney disease: challenges, progress, and possibilities. Clin. J. Am. Soc. Nephrol., 12(12):2032-45, 2017.

Aljohani, A.; Khan, M. I.;Bonneville, A.; Guo, C.; Jeffery, J.; O'Neill, L.; Syed, D. N.; Lewis, S. A.; Burhans, M.; Mukhtar, H.; et al. Hepatic stearoyl CoA desaturase 1 deficiency increases glucose uptake in adipose tissue partially through the PGC-1a-FGF21 axis in mice. $J$. Biol. Chem., 294(51):19475-85, 2019.

Bär, L.; Stournaras, C.; Lang, F. \& Föller, M. Regulation of fibroblast growth factor 23 (FGF23) in health and disease. FEBS Lett., 593(15):1879$900,2019$. 
Calle, P. \& Hotter, G. Macrophage phenotype and fibrosis in diabetic nephropathy. Int. J. Mol. Sci., 21(8):2806, 2020.

Cho, N. H.; Shaw, J. E.; Karuranga, S.; Huang, Y.; da Rocha Fernandes, J. D.; Ohlrogge, A. W. \& Malanda, B. IDF Diabetes Atlas: Global estimates of diabetes prevalence for 2017 and projections for 2045. Diabetes Res. Clin. Pract., 138:271-81, 2018.

Dias, T.; Bronze, M. R.; Houghton, P. J.; Mota-Filipe, H. \& Paulo, A. The flavonoid-rich fraction of Coreopsis tinctoria promotes glucose tolerance regain through pancreatic function recovery in streptozotocin-induced glucose-intolerant rats. J. Ethnopharmacol., 132(2):483-90, 2010a.

Dias, T.; Mota-Filipe, H.; Liu, B.; Jones, P.; Houghton, P. J. \& Paulo, A. Recovery of oral glucose tolerance by Wistar rats after treatment with Coreopsis tinctoria infusion. Phytother. Res., 24(5):699-705, 2010 b.

Donate-Correa, J. ;Luis-Rodríguez, D.; Martín-Núñez, E.; Tagua, V. G.; Hernández-Carballo, C.; Ferri, C.; Rodríguez-Rodríguez, A. E.; Mora-Fernández, C. \& Navarro-González, J. F. Inflammatory targets in diabetic nephropathy. J. Clin. Med., 9(2):458, 2020.

Fayed, A.; El Nokeety, M. M.; Heikal, A. A.; Abdulazim, D. O.; Naguib, M. M.; Sharaf El Din, U. A. A. \& Vascular Calcification Group (VCG). Fibroblast growth factor-23 is a strong predictor of insulin resistance among chronic kidney disease patients. Ren. Fail., 4O(1):226-30, 2018.

Guo, Y.; Ran, Z.; Zhang, Y.; Song, Z.; Wang, L.; Yao, L.; Zhang, M.; Xin, J. \& Mao, X. Marein ameliorates diabetic nephropathy by inhibiting renal sodium glucose transporter 2 and activating the AMPK signaling pathway in $\mathrm{db} / \mathrm{db}$ mice and high glucose-treated HK-2 cells. Biomed. Pharmacother, 131:110684, 2020.

Heerspink, H. J. L.; Parving, H. H.; Andress, D. L.; Bakris, G.; CorreaRotter, R.; Hou, F. F.; Kitzman, D. W.; Kohan, D.; Makino, H.; McMurray, J. J. V.; et al. Atrasentan and renal events in patients with type 2 diabetes and chronic kidney disease (SONAR): a doubleblind, randomised, placebo-controlled trial. Lancet, 393(10184):1937-47, 2019.

Huang, X.; Liu, G.; Guo, J. \& Su, Z. The PI3K/AKT pathway in obesity and type 2 diabetes. Int. J. Biol. Sci., 14(11):1483-96, 2018.

Hwang, I. G.; Kim, H. Y.; Shin, S. L.; Lee, C. H.; Lee, J.; Jang, K. I. \& Jeong, H. S. Biological activities of Coreopsis tinctoria Nutt. flower extracts. Korean J. Hortic. Sci. Technol., 28(5):857-63, 2010.

Jiang, B. P.; Lv, Q. Y.; Xiang, J. M.; Le, L.; Hu, K. P.; Xu, L. J. \& Xiao, P. G. Inhibition of metabolic disorders in vivo and in vitro by main constituent of Coreopsis tinctoria. Chin. Herb. Med., 10(2):157-68, 2018.

Jiang, B.; Le, L.; Zhai, W.; Wan, W.; Hu, K.; Yong, P.; He, C.; Xu, L. \& Xiao, P. Protective effects of marein on high glucose-induced glucose metabolic disorder in HepG2 cells. Phytomedicine, 23(9):891-900, 2016.

Lantier, L.; Williams, A. S.; Williams, I. M.; Guerin, A.; Bracy, D. P.; Goelzer, M.; Foretz, M.; Viollet, B.; Hughey, C. C. \& Wasserman, D. H. Reciprocity between skeletal muscle AMPK deletion and insulin action in diet-induced obese mice. Diabetes, 69(8):1636-49, 2020.

Li, W.; Du, M.; Wang, Q.; Ma, X.; Wu, L.; Guo, F.; Ji, H.; Huang, F. \& Qin, G. FoxO1 promotes mitophagy in the podocytes of diabetic male mice via the PINK1/Parkinpathway. Endocrinology, 158(7):2155-67, 2017.

Li, X.; Wu, C.; Lu, J.; Chen, B.; Li, Y.; Yang, Y.; Hu, S. \& Li, J. Cardiovascular risk factors in China: a nationwide population-based cohort study. Lancet Public Health, 5(12):e672-e681, 2020.

Liu, X.; Zhao, X.; Cheng, R. \& Huang, Y. Autophagy attenuates high glucose-induced oxidative injury to lens epithelial cells. Biosci. Rep., 40(4):BSR20193006, 2020.

Maffei, A.; Lembo, G. \& Carnevale, D. PI3Kinases in diabetes mellitus and its related complications. Int. J. Mol. Sci., 19(12):4098, 2018.

Mizushima, N. Autophagy: process and function. Genes Dev., 21(22):2861-73, 2007.
Moreno, J. A.; Gomez-Guerrero, C.; Mas, S.; Sanz, A. B.; Lorenzo, O.; Ruiz-Ortega, M.; Opazo, L.; Mezzano, S. \& Egido, J. Targeting inflammation in diabetic nephropathy: a tale of hope. Expert Opin. Investig. Drugs, 27(11):917-30, 2018.

Mottillo, E. P.; Desjardins, E. M.; Fritzen, A. M.; Zou, V. Z.; Crane, J. D.; Yabut, J. M.; Kiens, B.; Erion, D. M.; Lanba, A.; Granneman, J. G.; et al. FGF21 does not require adipocyte AMP-activated protein kinase (AMPK) or the phosphorylation of acetyl-CoA carboxylase (ACC) to mediate improvements in whole-body glucose homeostasis. Mol. Metab., 6(6):471-81, 2017.

$\mathrm{Mu}$, Y.; Zeng, H. \& Chen, W. Okanin in Coreopsis tinctoria Nutt is a major quorum-sensing inhibitor against Chromobacterium violaceum. J. Ethnopharmacol., 260:113017, 2020.

Müller-Wieland, D. Type 2 Diabetes Diabetes in Older Adults: Example for Patient-Centered Drug Therapy. Dtsch. Med. Wochenschr. 143(4):253-61, 2018.

Nunes, S.; Alves, A.; Preguiça, I.; Barbosa, A.; Vieira, P.; Mendes, F.; Martins, D.; Viana, S. D. \& Reis, F. Crescent-like lesions as an early signature of nephropathy in a rat model of prediabetes induced by a hypercaloric diet. Nutrients, 12(4):881, 2020.

Pina, A. F.; Borges, D. O.; Meneses, M. J.; Branco, P.; Birne, R.; Vilasi, A. \& Macedo, M. P.: Insulin: trigger and target of renal functions. Front. Cell Dev. Biol., 8:519, 2020.

Porrini, E.; Ruggenenti, P.; Mogensen, C. E.; Barlovic, D. P.; Praga, M.; Cruzado, J. M.; Hojs, R.; Abbate, M. \& de Vries, A. P. Nonproteinuric pathways in loss of renal function in patients with type 2 diabetes. Lancet Diabetes Endocrinol., 3(5):382-91, 2015.

Sagoo, M. K. \& Gnudi, L. Diabetic nephropathy: Is there a role for oxidative stress? Free Radic. Biol. Med., 116:50-63, 2018.

Shintani, T. \& Klionsky, D. J. Autophagy in health and disease: a doubleedged sword. Science, 306(5698):990-5, 2004.

Talukdar, S.; Zhou, Y.; Li, D.; Rossulek, M.; Dong, J.; Somayaji, V.; Weng, Y.; Clark, R.; Lanba, A.; Owen, B. M.; et al. A Long-Acting FGF21 Molecule, PF-05231023, decreases body weight and improves lipid profile in non-human primates and type 2 diabetic subjects. Cell Metab., 23(3):427-40, 2016.

Thomas, S. \& Karalliedde, J.: Diabetic nephropathy. Medicine, 47(2):86-91, 2019

Trummer, C.; Schwetz, V.; Pandis, M.; Grübler, M. R.; Verheyen, N.; Gaksch, M.; Zittermann, A.; März, W.; Aberer, F.; Steinkellner, J.; et al. Effects of vitamin D supplementation on FGF23: a randomized-controlled trial. Eur. J. Nutr., 58(2):697-703, 2019.

Umanath, K. \& Lewis, J. B.: Update on Diabetic Nephropathy: Core Curriculum 2018. Am. J. Kidney Dis., 71(6):884-95, 2018.

Wang, T.; Xi, M. \& Guo, Q. Chemical components and antioxidant activity of volatile oil of a Compositae tea (Coreopsis tinctoria Nutt.) from Mt. Kunlun. Ind. Crops Prod., 67:318-23, 2015.

Wang, Z. F. Advances in the research of drug therapy for diabetes. Chin. Foreign Med. Res., 16:186-8, 2018.

Wang, Z.; Huang, J.; Zhou, S.; Luo, F.; Tan, Q.; Sun, X.; Ni, Z.; Chen, H.; Du, X.; Xie, Y.; et al. Loss of Fgfr1 in chondrocytes inhibits osteoarthritis by promoting autophagic activity in temporomandibular joint. J. Biol. Chem., 293(23):8761-74, 2018.

Wei, Y.; Li, M. \& Yu, J. Research progress in the relationship between chronic inflammation and insulin resistance. J. Clin. Pathol. Res., 39:640-5, 2019.

Wen, D.; Tan, R. Z.; Zhao, C. Y.; Li, J. C.; Zhong, X.; Diao, H.; Lin, X.; Duan, D. D.; Fan, J. M.; Xie, X. S.; et al. Astragalus mongholicus Bunge and Panax notoginseng(Burkill) F.H. Chen formula for renal injury in diabetic nephropathy- in vivo and in vitro evidence for autophagy regulation. Front. Pharmacol., 11:732, 2020.

Xu, L. L.; Gao, W.; Chen, Z. M.; Shao, K. K.; Wang, Y. G.; L, L. C. \& Guo, N. Z. Relationships between diabetic nephropathy and insulin resistance, inflammation, Trx, Txnip, CysC and serum complement levels. Eur. Rev. Med. Pharmacol. Sci., 24(22):11700-6, 2020. 
Yamamoto, S.; Koyama, D.; Igarashi, R.; Maki, T.; Mizuno, H.; Furukawa, Y. \& Kuro, O. M. Serum endocrine fibroblast growth factors as potential biomarkers for chronic kidney disease and various metabolic dysfunctions in aged patients. Int. Med., 59(3):345-55, 2020.

Yang, L.; Lin, H.; Lin, W. \& Xu, X. Exercise ameliorates insulin resistance of type 2 diabetes through motivating short-chain fatty acid-mediated skeletal muscle cell autophagy. Biology (Basel), $9(8): 203,2020$.

Yao, L.; Li, L.; Li, X.; Li, H.; Zhang, Y.; Zhang, R.; Wang, J. \& Mao, X. The anti-inflammatory and antifibrotic effects of Coreopsis tinctoria Nutt on high-glucose-fat diet and streptozotocin-induced diabetic renal damage in rats. BMC Complement. Altern. Med., 15:314, 2015.

Yashkin, A. P.; Kravchenko, J.; Yashin, A. I. \& Sloan, F. Mortality and macrovascular risk in elderly with hypertension and diabetes: effect of intensive drug therapy. Am. J. Hypertens., 31(2):220-7, 2018.

Yuan, H.; Li, Z. M.; Shao, J.; Ji, W. X.; Xia, W. \& Lu, S. FGF2/FGFR1 regulates autophagy in FGFR1-amplified non-small cell lung cancer cells. J. Exp. Clin. Cancer Res., 36(1):72, 2017.

Zhang, X.; Guo, K.; Xia, F.; Zhao, X.; Huang, Z. \& Niu, J. FGF23 Ctail improves diabetic nephropathy by attenuating renal fibrosis and inflammation. BMC Biotechnol., 18(1):33, 2018.

Zhang, Y.; Wang, Y.; Luo, M.; Xu, F.; Lu, Y.; Zhou, X.; Cui, W. \& Miao, L. Elabela protects against podocyte injury in mice with streptozocin-induced diabetes by associating with the PI3K/Akt/ mTOR pathway. Peptides, 114:29-37, 2019.

\author{
Corresponding author: \\ Xinmin Mao \\ College of Traditional Chinese Medicine \\ Xinjiang Medical University \\ No. 393, Xinyi Street 393 \\ Urumqi Xinjiang \\ CHINA
}

E-mail: mxm13565843968@126.com

Received: 25-07-2021

Accepted: 31-08-2021 